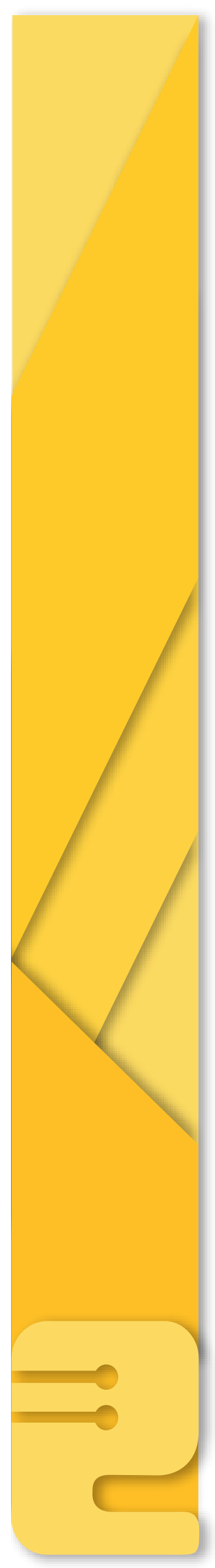

\title{
PROPUESTA DE IDENTIFICACIÓN DE PATRONES RETICULARES EN TOMOGRAFÍAS AXIALES COMPUTARIZADAS DEL PULMÓN HUMANO BASADA EN CONTORNOS
}

\author{
INDENTIFICATION PROPOSAL ABOUT RETICULATED PATTERNS IN COMPUTERIZED AXIAL \\ TOMOGRAPHYS OF HUMAN LUNG WITH RELATION TO ENVIRONS \\ PROPOSTA IDENTIFICAR PADRÕES RETICULARES EM TOMOGRAFIA COMPUTADORIZADA \\ DO PULMÃO HUMANO COM BASE EM CONTORNOS
}

Juan David Prieto Rodriguez¹, Pamela Andrea Hernández Gaona², Natalia Manrique Avellaneda

Fecha de recibido: Febrero 01 de 2016 | Fecha de aprobado: Marzo 31 de 2016

\section{Resumen}

Con la inclusión de la tecnología digital en los procedimientos médicos y especialmente en el diagnóstico de imágenes clínicas, se hace necesario automatizar el proceso de identificación de las condiciones clínicas de manera oportuna, contribuyendo de este modo a la implementación del concepto de telemedicina. Por esta razón, las técnicas de procesamiento digital de imágenes son una alternativa para proveer diagnósticos, conceptos médicos o sugerir soluciones sin demeritar por ello la apreciación de un especialista. Este artículo centra su estudio en la implementación de dos técnicas de procesamiento digital de imágenes: identificación de bordes y contornos (concepto que deriva del primero) e identificación de patrones por ajuste de contraste, así se apunta a identificar cuál es el más apropiado para caracterizar un típico patrón enrejado, aspecto de la neumonía que afecta los pulmones humanos.

Asimismo, se presenta una propuesta de acondicionamiento de imágenes diagnósticas del pulmón para que puedan ser sometidas técnicas de procesamiento para identificar patrones reticulares y alveolares, características propias de la neumonía en los humanos.

Palabras clave: pulmones, tomografía computarizada, neumonía, procesamiento digital de imágenes.

1 Corporación Universitaria Minuto de Dios - UNIMINUTO. Facultad de Ingeniería - Tecnología en Gestión de la seguridad de las redes de computadores. Bogotá, Colombia. Correo electrónico: juan.prieto@uniminuto.edu.co

2 Fundación Universitaria San Martin. Correo electrónico: ph081082@ingenieria.sanmartin.edu.co

3 Estudiante de Tecnología en Redes y Seguridad de Computadores. Corporación Universitaria Minuto de Dios-UNIMINUTO. Correo electrónico: nmanriqueav@gmail.com 


\section{Abstract}

With the inclusion of digital technology in medical procedures and especially in the diagnosis of medical images, it is necessary to automate the process of identification of clinical conditions in a timely manner, thus contributing to the implementation of the concept of telemedicine. For this reason, the techniques of digital image processing are an alternative to provide diagnostic medical concepts suggest solutions without detracting from the appreciation of the specialist. This article focuses its study on the implementation of two techniques of digital image processing: identifying edges and contours (concept of the first and second derivative) and identification of patterns by contrast adjustments, thus aims to identify which is the more appropriate to characterize a typical lattice pattern, aspect pneumonia disease afflicting the human lung.

Keywords: lungs, computarized tomography, pneumonia, digital image processing.

\section{Resumo}

Com a inclusão da tecnologia digital na medicina e, especialmente, no diagnóstico de imagiologia procedimentos clínicos, é necessário para automatizar o processo de identificação de condições clínicas em tempo hábil, contribuindo assim para a implementação do conceito de telemedicina. Por esta razão, as técnicas de processamento digital de imagens são uma alternativa para fornecer, conceitos médicos de diagnóstico ou sugerir soluções para isso sem desacreditar a apreciação de um especialista. Este artigo se concentra o seu estudo sobre a aplicação de duas técnicas de processamento digital de imagens: identificar bordas e contornos (conceito derivado do primeiro) e identificação de padrões, ajustando contraste e tem como objetivo identificar o que é o mais adequado para caracterizar um aspecto típico de padrão de retículo de pneumonia que afectam os pulmões humanos. uma imagem de diagnóstico condicionado proposta do pulmão também parece ser submetido a técnicas de processamento para identificar e reticular padrões alveolares, características de pneumonia em seres humanos.

Palavras-chave: pulmões, ст, pneumonia, processamento de imagem digital. 


\section{INTRODUCCIÓN}

EL continuo avance de las telecomunicaciones ha permitido que se desarrollen nuevas tecnologías enfocadas en áreas específicas (Eusko Jaurlaritzaren Argitalpen Zerbitzu Nagusia, 2012). Una de estas tecnologías ha sido el concepto de telemedicina, orientada a la rama médica, la cual se caracteriza por permitir la emisión de consulta, diagnóstico y tratamiento a distancia mediante conferencia y asistencia remota. Como esta tecnología se puede clasificar como servicio, la presente investigación estará dirigida hasta la parte del telediagnóstico, el cual permite al médico profesional dar soporte remoto, obtener la información de los pacientes, disminuir las listas de espera y aumentar la productividad de los centros de salud (Series Tecnológicas: Volumen 3 Telemedicina, 2011).

Por las razones nombradas anteriormente, se desea implementar la telemedicina utilizando una herramienta de ayuda semi-independiente del control humano que agilice el proceso de análisis de resultados; se detecta de esta manera patrones específicos que identifiquen alguna enfermedad del paciente y se ayuda al médico a generar un análisis más preciso para diagnosticar de manera más acertada y a tiempo al paciente. Esta herramienta utilizará los sistemas de procesamiento digital de imágenes, los cuales han permitido al médico tomar decisiones basándose en el contenido de una imagen que revela cualquier padecimiento en el cuerpo humano.

\section{MARCO TEÓRICO}

Entre los descubrimientos que han servido como herramientas eficaces y son de suma importancia en el campo de la medicina para poder detectar y diagnosticar enfermedades en los pacientes encontramos: rayos $\mathrm{X}$, ultrasonido, radiactividad, resonancia magnética y tomografía axiales computarizadas. El objetivo de este tipo de exámenes es permitir de alguna manera al médico tratante la exploración a profundidad de los órganos.

\section{TOMOGRAFÍA AXIAL COMPUTARIZADA}

En el caso de las tomografías axiales computarizadas, los fundamentos matemáticos desarrollaron fórmulas capaces de reconstruir una imagen tridimensional a partir de múltiples imágenes planas; es considerado un método de imagenología que se usa para el diagnóstico médico pues permite observa de esta manera el interior del cuerpo humano, específicamente el órgano a tratar mediante milimétricos cortes transversales.

Dentro de los usos que se le dan a este método cabe resaltar la detección de tumores cerebrales, accidentes vasculares, aneurismas, infecciones torácicas, enfermedades de órganos, entre otros. En ocasiones, para una mejor visualización, se pueden llegar a utilizar medios de contraste que permitan que la imagen pueda verse más nítida.

\section{PROCESAMIENTO DIGITAL DE IMÁGENES -PDI-}

Técnicas que se utilizan con el objetivo de agilizar y ayudar a la interpretación de la información contenida en la imagen. Estas técnicas usan algoritmos que, implementados en la imagen, obtienen filtrado, segmentación y restauración de señales, mejorando de esta manera la calidad de la información para su interpretación posterior.

Su característica de mejoramiento involucra a este método de análisis dentro del campo de la medicina, lo cual ha permitido determinar, diagnosticar y tratar al paciente.

En el desarrollo de esta investigación fue necesario utilizar las etapas del procesamiento digital de imágenes. Ver figura 1. Cada una de las etapas del PDI se caracteriza porque puede hacer uso de la llamada base del conocimiento, además dentro del procesamiento existen cuatro niveles que se clasifican de acuerdo al nivel de dificultad de las tareas presentes en cada etapa. (Calvo, 2004; Corbo, 2004).

1. La primera etapa es la de adquisión de la imagen y la de preprocesamiento: se distingue por utilizar técnicas para el mejoramiento de la imagen que faciliten la extracción de características.

Figura 1. Esquema del procesamiento digital de imágenes

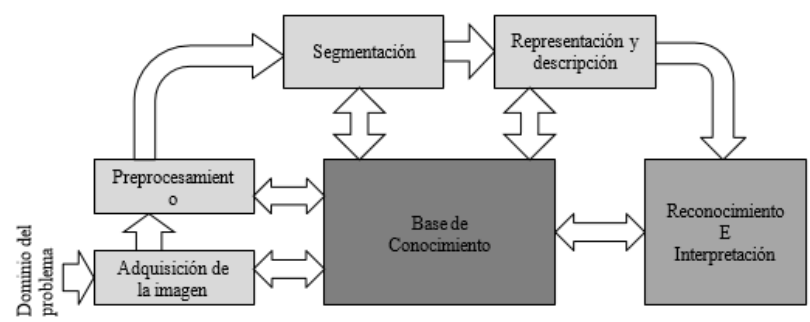

Fuente: Cuevas Jimenez, Zaldivar Navarro, y Perez Cisneros, 2010. 
Un ejemplo: de las técnicas de preprocesamiento es la de contraste. Ver figura 2.

2. La segunda etapa es la de segmentación: puede representarse el objeto a analizar con base en características tales como el contorno o la textura.

Figura 2. (a) Imagen original; (b) imagen con modificación de contraste

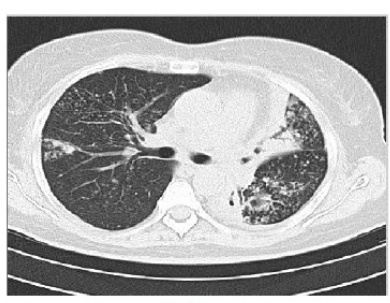

(a)

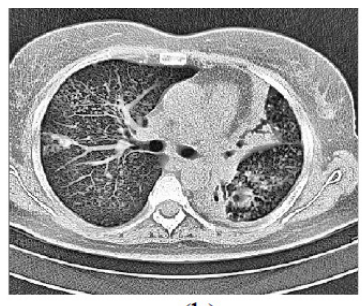

(b)

Fuente: elaboración propia.

3. La tercera etapa es la de reconocimiento e interpretación: se caracteriza porque se diferencia la información que se desea tratar patrón-.

Figura 3. Visualización del contorno de la imagen

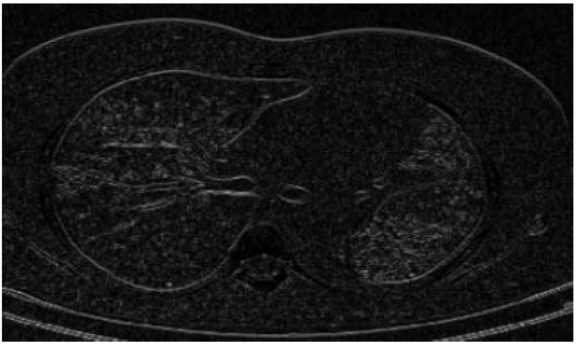

Fuente: elaboración propia.

anteriormente, el $20 \%$ otros patrones y el $10 \%$ fueron tomografías de pacientes sanos.

El patrón que se trabajará a lo largo de esta investigación será el patrón reticular -ver figura 4-. Este patrón es uno de los que se llega a presentar cuando un paciente presenta neumonía, proceso infeccioso del parénquima pulmonar que ocasiona una inflamación de los bronquiolos, lo cual causa que los sacos de aire de los pulmones se llenen de mucosa y otros líquidos, dificultando la llegada del oxígeno a la sangre. El patrón visible dentro de las tomografías axiales computarizadas y por lo general, presentan tamaño y contrastes notorios y específicos. (Corbo, 2004).

Figura 4. Patrón reticular presente cuando un paciente tiene neumonía

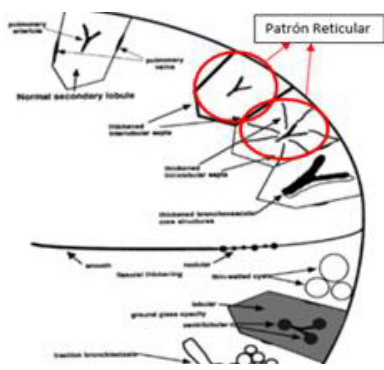

Fuente: Escribano Montaner y Moreno Galdó, 2005.

El patrón reticular afecta principalmente a los septos interlobulares haciéndolos engrosar. Los septos se componen de tejido conectivo que contienen vasos linfáticos y venas pulmonares. En los hallazgos radiológicos el engrosamiento de los septos interlobulares localizados en la porción central del parénquima pulmonar produce imágenes lineales u opacidades lineales de varios centímetros de longitud. Ver figura 5 (Medina, s.f.).

Figura 5. Engrosamiento de los septos interlobulillares, TAC -Patrón reticular-

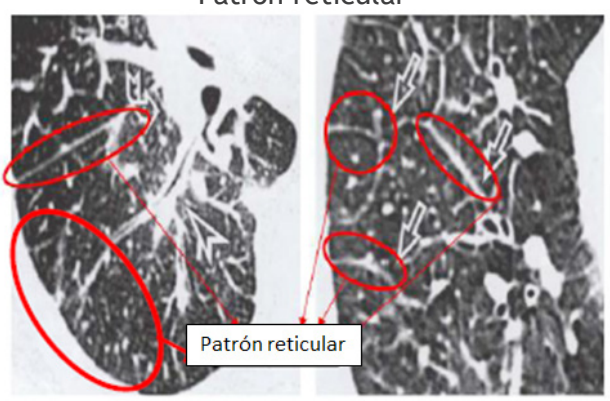

Fuente: SEPAR, 2010.

Después de conocer las características esenciales del patrón reticular, se procede a aplicar dos una base de datos de 50 tomografías, de las cuales el $70 \%$ de ellas presentó el patrón nombrado 
técnicas de procesamiento digital de imágenes con el propósito de escoger cuál de las dos es la mejor para determinar dichas características.

Las técnicas a implementar son:

A. Identificación de patrón reticular por contornos.

B. Identificación de patrón reticular por realce de brillo y contraste.

\section{IDENTIFICACIÓN DE PATRÓN RETICULAR POR FILTROS}

Para la identificación de este patrón fue necesario hacer uso de los filtros Sobel, Prewitt y Canny.

De esta manera, la derivada parcial discretizada es considerada como una función multidimensional al lado de un eje coordenado, produciendo así una elevación positiva en valor del pixel en la que la intensidad de la tomografía aumenta y una negativa en la que la intensidad disminuye:

$$
\frac{d f}{d u}(u) \approx \frac{f(u+1)-f(u-1)}{2}
$$

Fuente: Cuevas Jimenez, Zaldivar Navarro, \& Perez Cisneros, 2010.

Donde se expresa la derivada parcial en función de la tomografía axial $I(u, v)$ respecto a la variable discretizada ("u o v"), así:

$$
\nabla I(u, v)=\left|\begin{array}{l}
\frac{\partial I}{\partial u}(u, v) \\
\frac{d I}{d v}(u, v)
\end{array}\right|
$$

Ecuación 2.

Fuente: Cuevas Jimenez, Zaldivar Navarro, \& Perez Cisneros, 2010.

Donde el vector gradiente indica la dirección en la cual cambia la intensidad de los pixeles $I(u, v)$; se identifican así los bordes dado que en estos puntos la energía -intensidad-cambia más rápidamente:

$$
|\nabla I|=\sqrt{\frac{\left(\frac{\partial I}{\partial u}\right)^{2}+\left(\frac{\partial I}{\partial v}\right)^{2}}{\text { Ecuación 3. }}}
$$

Fuente: Cuevas Jimenez, Zaldivar Navarro, \& Perez Cisneros, 2010.

Con el cálculo del gradiente se garantiza que el cálculo de los bordes y contornos en la tomografía sea invariante a las rotaciones e independiente a las formas de las estructuras orgánicas que éstas contiene. Tal es la razón por la cual identificar la dirección de los cambios abruptos en la intensidad de los pixeles sirve para identificar los bordes de las estructuras orgánicas del pulmón dentro de la tomografía que está siendo sometida a estudio.

La implementación del cálculo del gradiente de manera local por pixel de la imagen hace la diferencia en la identificación de los contornos y bordes contenidos en la tomografía, por ello se ejecuta a través de filtros que obedezcan a la siguiente estructura de procesamiento:

Figura 6. Estructura de procesamiento de los filtros

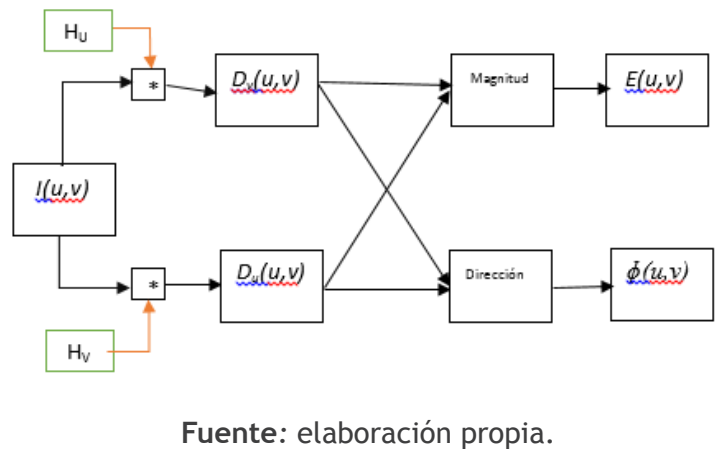

Algoritmo de identificación de bordes y contornos en tomografía axial con filtros:

Para la identificación de bordes y contornos sobre las tomografías se aplicaron los siguientes procedimientos: 
Figura 7. Diagrama de flujo identificación de bordes

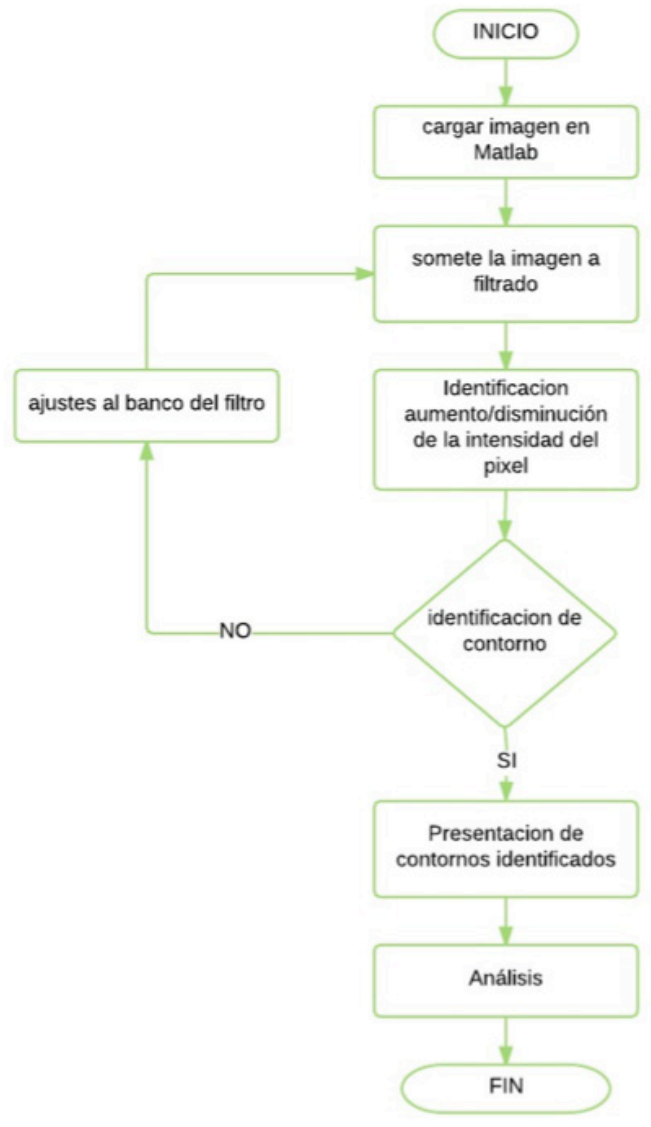

Fuente: elaboración propia.

Donde el cálculo del gradiente es un factor importante en el ajuste del banco del filtro.

\section{PRUEBAS Y RESULTADOS}

Se sometieron al algoritmo propuesto un banco de tomografías axiales del pulmón con el fin de determinar el patrón reticular que origina una patología como la neumonía. En la figura 8 se aprecia en la parte demarcada el patrón visual que diagnostica el especialista en medicina.

Figura 8. Demarcación del patrón reticular

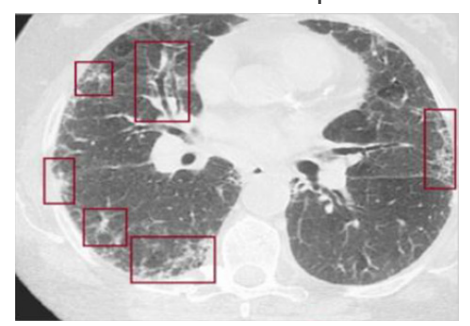

Fuente: adaptación de los autores.
La imagen fue sometida a banco de filtros Sobel, los cuales calculan el gradiente del pixel en dos direcciones, de manera horizontal y vertical, logrando de ese modo una aproximación a la dirección en la que la intensidad del pixel cambia más rápido. En la figura 9 se observan los contornos sobre la tomografía erosionados, partes en las que es difícil identificar visualmente el patrón reticular. Dicha imagen fue sometida a los filtros Prewitt y los coeficientes de estos son parámetros similares a los Sobel: incrementan el valor de « $X$ » escalar tanto para los verticales como los horizontales.

Figura 9. Filtro Prewitt

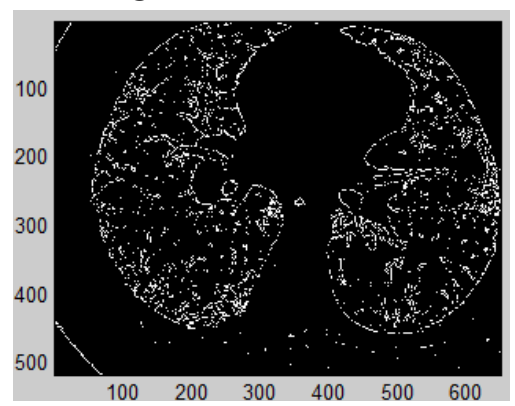

Fuente: adaptación de los autores.

La figura 10 muestra el resultado del procesamiento de la imagen. Se observa mucha más erosión respecto a la imagen sometida con filtros Sobel. Esto hace imposible la identificación de algún patrón.

Figura 10. Filtro Sobel

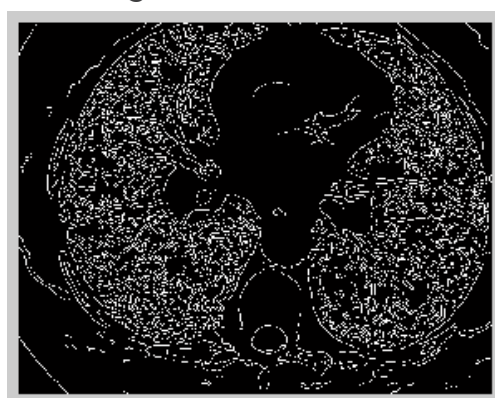

Fuente: adaptación de los autores.

Al someter la tomografía a los filtros Canny, se observa una identificación más precisa de los gradientes de la imagen. Resaltan así los bordes en los que los cambios de intensidad son leves ver figura 11-; de forma similar, se observa erosión en los bordes identificados, por tanto, es necesario hacer interpolación sobre la imagen con el fin de definir los contornos y así poder determinar de manera más precisa el patrón reticular o alveolar. 
Figura 11. Filtro Canny

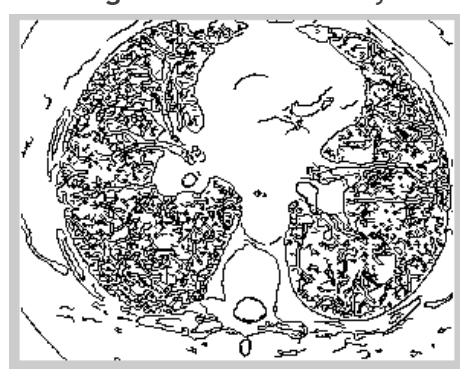

Fuente: adaptación de los autores.

De acuerdo al resultado obtenido con los filtros Canny, se observa que se identifican claramente los bordes y contornos del pulmón, encontrando las formas de los alveolos y los septos interlobulillares, este último un patrón característico de la neumonía (ver figura 12).

\section{Figura 12. Filtro Canny}

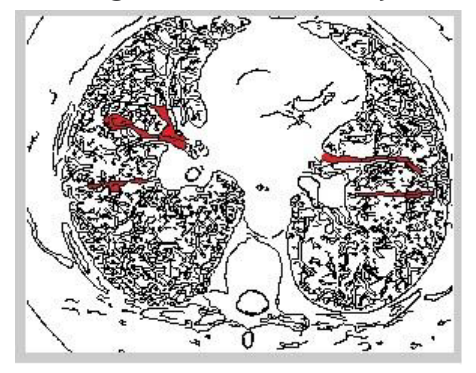

Fuente: adaptación de los autores.

Identificando los bordes y contornos se observan partes propias del pulmón, lo que hace que la identificación del patrón de la enfermedad deba ser elaborada por expertos. Este se debe a que los patrones reticulares se pierden en el proceso de filtrado porque corresponden a una textura suave dentro de la imagen - parecida a una nubosidad al ojo humano-; respecto a los septos interlobulillares, tiende a confundirse con la estructura interna del pulmón -ver figura 13-.

Figura 13. Filtro Canny

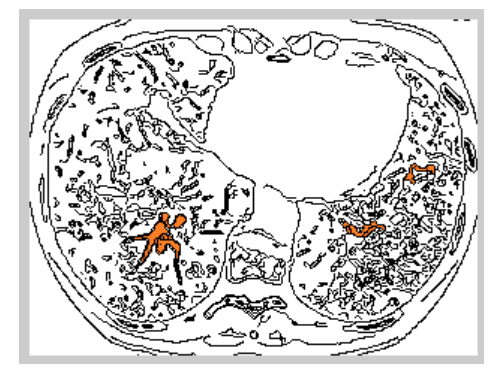

Fuente: adaptación de los autores.

\section{IDENTIFICACIÓN DE PATRÓN RETICULAR POR AJUSTE DE CONTRASTE}

Para la identificación del patrón reticular por medio del realce y ajuste de contraste será necesario utilizar técnicas que permitan la manipulación de histograma, un gráfico que relaciona niveles de intensidad de gris con el número de píxeles que hay para cada nivel.

Para la identificación de los patrones será necesario realizar las siguientes acciones:

Algoritmo de identificación de contornos en TAC con ajuste de contraste:

Figura 14. Diagrama de flujo para identificar patrones reticulares con ajuste de contraste

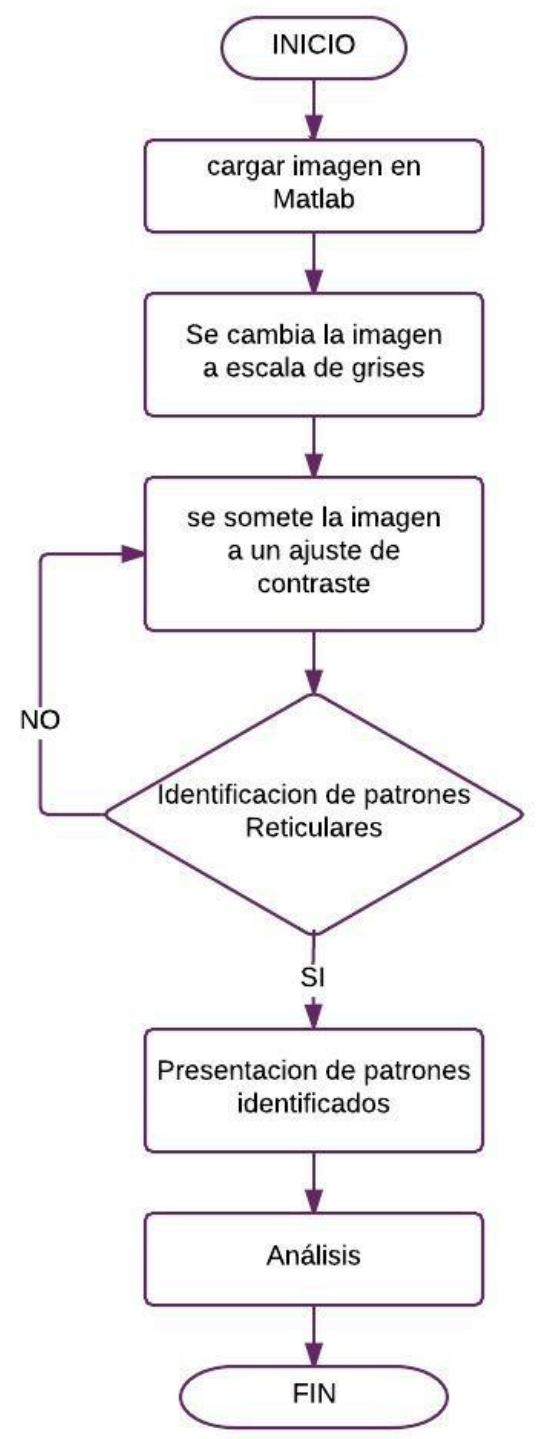

Fuente: adaptación de los autores. 


\section{PRUEBAS Y RESULTADOS}

La imagen a evaluar con estas técnicas es -ver figura 15-:

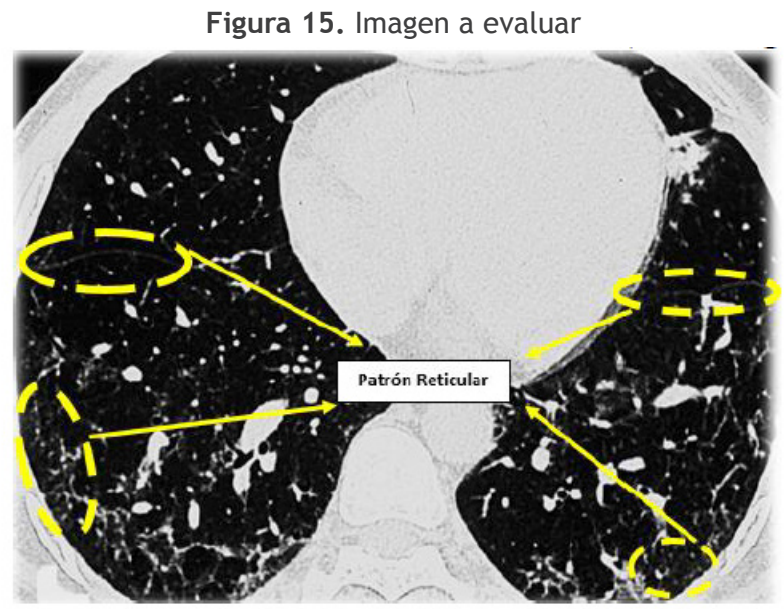

Fuente: adaptación de los autores.

Se debe tener presente que la imagen anterior necesita ser cambiada a la escala de grises. De otro lado, el patrón reticular señalado por una demarcación no se contempla a simple vista y, por ello, se necesita ajustar brillos y contrastes para poder visualizarlo de mejor forma. Las técnicas a utilizar serán las siguientes:

A. Técnicas de Imadjust: se caracteriza por expandir el histograma ajustando todos los valores de intensidad de la imagen en un rango determinado para una mejor visualización de los niveles de intensidad.

En la imagen anterior puede visualizarse un poco mejor los patrones reticulares.
B. Técnicas de Histeq: se encargan de ecualizar el histograma actuando sobre la imagen completa Figura 17. Imagen procesada por Histeq

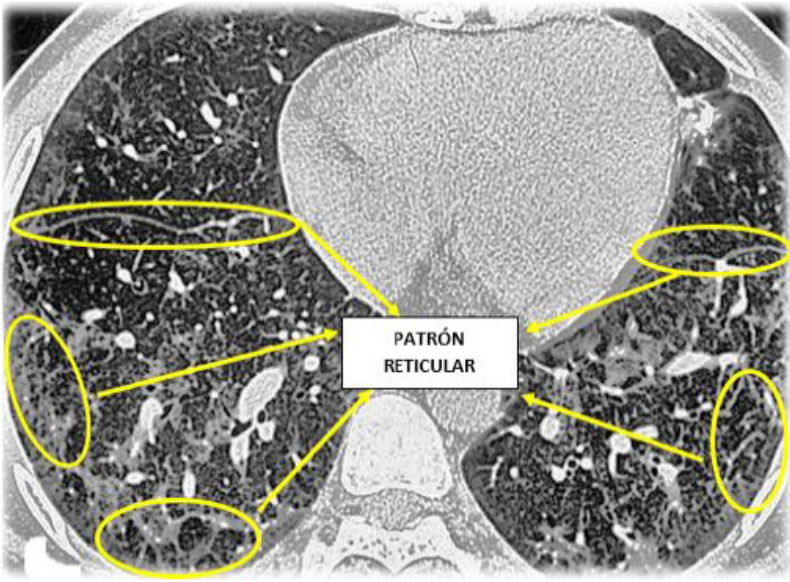

Fuente: adaptación de los autores.

C. Técnicas de Adapthisteq-Clahe-: se distingue por mejorar el contraste de la imagen utilizando una ecualización del histograma. Esta técnica es importante porque permite marcar los detalles de una imagen y perfeccionar el contraste general de la misma.

Figura 18. Imagen procesada con Adapthisteq

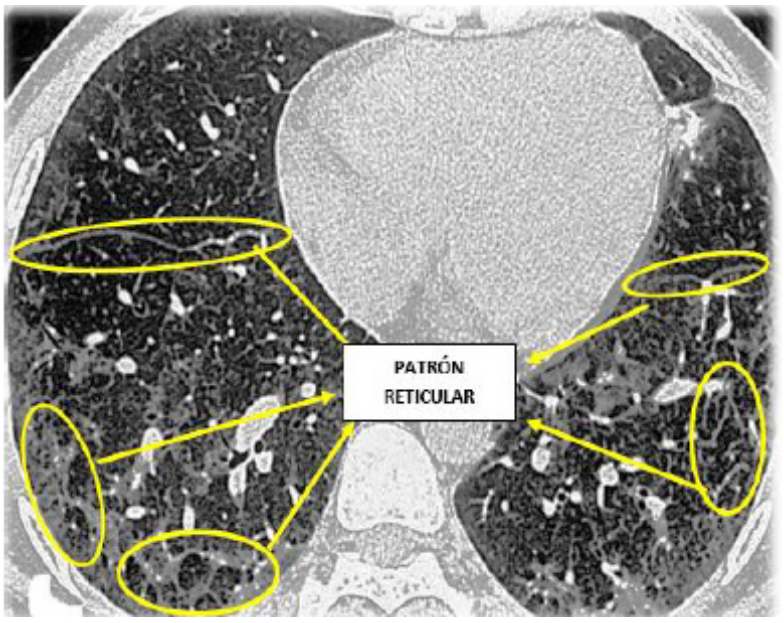

Fuente: adaptación de los autores.

Después de procesar la imagen con las técnicas de contraste podemos darnos cuenta de que el patrón se puede observar con mayor facilidad. Y mediante el análisis de los histogramas que nos presentan cada una de las imágenes podemos decir que la técnica Adapthisteq -último histograma de la figura 19.brinda mucha más información que el resto en vista que resalta más los detalles y distribuye en su totalidad el nivel de pixeles. 
Figura 19. Histogramas de las técnicas con ajuste de contraste

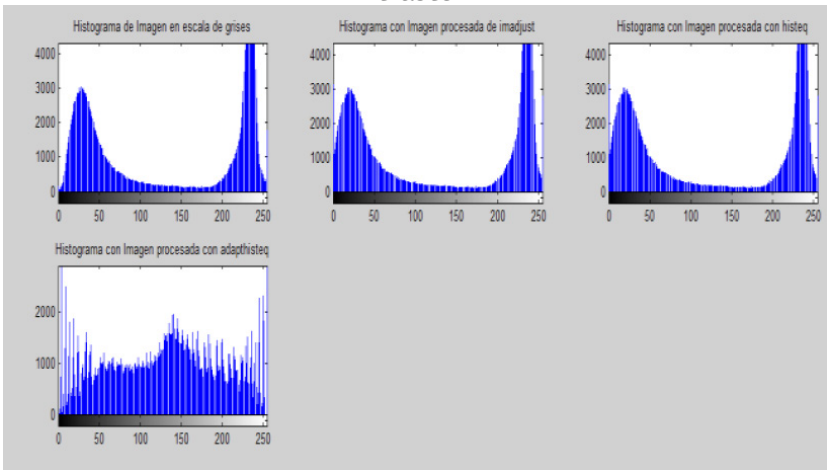

Fuente: adaptación de los autores.

A partir de aquí la imagen será procesada para la detección de bordes y de esta manera corroborar si finalmente puede visualizarse el patrón con esta técnica.

Figura 20. imagen procesada por ajuste de contraste y posteriormente con detección de bordes

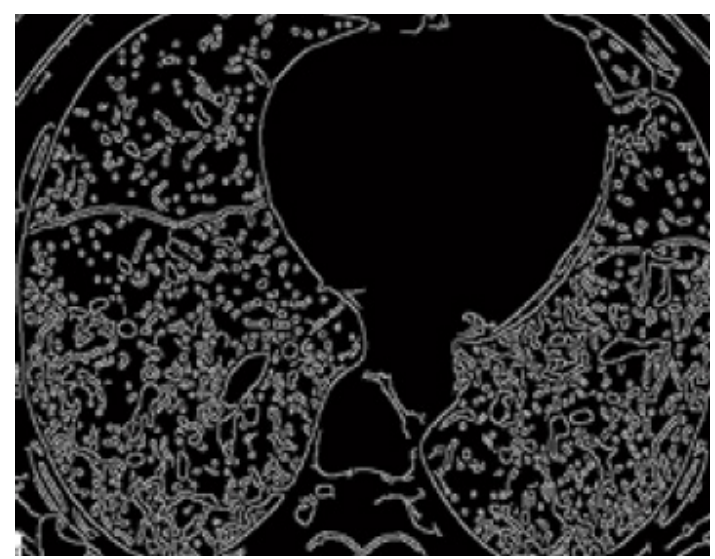

Fuente: adaptación de los autores.

La imagen 20 nos muestra la detección de bordes de una imagen con ajuste contraste; quien conozca las características de los patrones podrá argumentar que esta técnica permite determinar el patrón reticular, pero a quien no las conozca se le dificultará verlo.

\section{CONCLUSIONES}

Después de ejecutadas y analizadas ambas técnicas, se puede concluir que la detección de bordes para ambas no logra brindar mucha información con respecto a la determinación de los patrones reticulares. A simple vista, y siempre y cuando el analista de imágenes diagnósticas tenga conocimiento de dicho patrón, podrá ubicar de manera más fácil la presencia de ésta, pero si el espectador que no tiene dichos conocimientos no sabrá su ubicación.

Por otra parte, la idea del mejoramiento de la imagen se da con el propósito de mejorar y agilizar la interpretación y visualización de la información contenida en cada una de las imágenes, en este caso, del patrón reticular que identifica la patología de la neumonía.

El objetivo de la presente investigación es brindar un apoyo al usuario que las analiza para emitir un posible diagnóstico de lo que padece un paciente sin excluir el criterio del médico tratante.

La técnica de contraste generalmente es utilizada como una técnica de preprocesamiento para mejorar $y$, asimismo, permitir demarcar más los patrones reticulares de las imágenes originales con el fin de visualizar más rápidamente los patrones y agilizar el proceso de análisis de los mismos.

La detección de bordes para esta investigación cumple un papel primordial pues, al aplicarlo sobre las imágenes diagnósticas, posibilita diferenciar el patrón estudio del resto de componentes que conformaban la imagen.

El patrón reticular por lo general se logra observar en las tomografías axiales computarizadas cuando hay engrosamiento de los septos interlobulillares, dando a entender que el paciente está empezando a sufrir o está sufriendo alguna patología. Se debe considerar, y esto es de gran importancia, que en varias enfermedades este patrón puede estar presente, así como en una misma enfermedad pueden existir varios patrones. La decisión que se tomó en esta investigación es que dicho patrón, tanto para la neumonía como para sus derivadas, es el que predomina.

Dentro de los trabajos a futuro que se plantearon gracias a este estudio está la creación de una herramienta -aplicación- capaz de servir como herramienta de apoyo y ayuda al diagnóstico de pacientes que presenten la patología de la neumonía. 


\section{REFERENCIAS}

Calvo, J.M. (2004). Neumonía de la Comunidad. Referencia Completa: Calvo Bonachera, J. (2004). Neumonías de la comunidad. Almeria - España: Hospital Torrecárdenas.

Corbo, D. (2004). Tomografía Axial Computarizada. Referencia Completa: Corbo Pereira, D. N. (2004) - Facultades de medicina e ingeniería - Universidad de la República Oriental del Uruguay - Montivideo). Tomografía Axial Computada. Núcleo de ingeniería biomédica.

Gordillo, N. (2012). Introducción a la ingeniería Biomedica. Referencia Completa: Rojas, M. D., Ruiz Ruiz, C., \& Gordillo, N. (2010). Introducción a la Ingeniería Biomédica. Bogotá - Colombia: Ediciones de la U.
Medina, R. (s.f). Bases del procesamiento de imágenes. Referencia Completa: Medina, R., \& Bellera, J. (2001). Bases del Procesamiento de Imágenes Médicas. Merida - Venezuela: Universidad de Los Andes (Venezuela) - Facultad de Ingeniería - Grupo de Ingeniería Biomédica de la ULA (GIBULA).

Navarro, S. (s.f). Técnicas Radiológicas Especiales. Referencia Completa: Serrano Gotarredona, M., Aguilar Sánchez, L., Navarro Herrero, S., \& Fernández Cruz, J. (2006). Técnicas radiológicas especiales y aplicación en neumología: TAC, RM y PET. Revista Española de Patología Torácica, $61-75$. 